\title{
A study of reproductive morbidity of women in the Eastern Terai Region of Nepal
}

\author{
Ganesh Dangal \\ Kathmandu Model Hospital
}

\begin{abstract}
Aim: This study aims to fill the gap of information of reproductive health $(\mathrm{RH})$ of women living in rural eastern Terai by providing baseline data on reproductive morbidity (RM) leading to pelvic organ prolapse $(\mathrm{POP})$, reproductive tract infections (RTIs), menstrual problems and subfertility.

Methods: This is a descriptive analysis of women who attended mobile RH camps in eastern Terai of Nepal organized at different villages falling in three districts namely Rautahat, Mahottari and Saptari during December 2005 and 2006.

The diagnoses were made mostly on clinical evaluation and treatment provided. The leading reproductive morbidity of POP was dealt in detail and surgeries were performed in the district headquarters.

The data were recorded and analysed manually. Analysis was done by standard statistical methods and a two tailed $\mathrm{P}$ value less than 0.05 was considered to indicate a significant difference.

Results: Total number of women treated in the camps was 7750. Majority of the women in this study were found to be suffering from STI (30.1\%), followed by POP (20.1\%), menstrual disorders (16.7\%) and subfertility (9.3\%). Among POP patients majority received ring pessary insertion (43.8\%) followed by counseling plus pelvic floor exercise (32.9\%) and surgical correction (23.3\%). Third-degree POP (38.6\%) was commonest among all POP cases. Majority (60\%) developed POP after first and second child birth.

Conclusion: The major reproductive morbidity in this study was STI, POP (most of the women having thirddegree uterovaginal prolapse), menstrual disorders and sub-fertility. Surgical treatment at the camps could only be provided to small number, suggesting expansion of health services in rural Nepal by reproductive health barriers like poverty, education.
\end{abstract}

Key words: menstrual disorders, pelvic organ prolapse, reproductive morbidity, reproductive tract infections, sub-fertility.

\section{Introduction}

Reproductive health and women's health in general were looked at in a more holistic way since the International Conference on Population and Development (ICPD) in Cairo in 1994. ${ }^{1}$ The concept of reproductive health as a central component of women's development was further endorsed during the Fourth World Congress on Women held in Beijing in 1995. Reproductive morbidity is a broad concept that encompasses obstetric morbidity including conditions during pregnancy, delivery and the post-partum period; and gynecological morbidity including conditions of ill health unrelated to pregnancy such as reproductive tract infections, cervical cell changes, genital prolapse, malignancies and sub-fertility. Reproductive morbidity in general, is an outcome of not just biological factors but of women's poverty, powerlessness and lack of control over resources as well. It affects the health and social well being of women, particularly those in the reproductive and economically most productive age groups, and their offspring. There is a sharp disparity between the developing and developed countries in context of reproductive health. The magnitude of women's reproductive health problems in developing countries is immense. Reproductive health status of

Correspondence

Dr. Ganesh Dangal, MD

Conslultnant, Kathmandu Model Hospital

Email:gareshma@hotmail.com 
the third world women as indicated by available indicator of maternal mortality is very alarming.

$\mathrm{RH}$ is a major public health issue in Nepal also. The high maternal mortality in Nepal occurs during pregnancy, childbirth, post-partum period and during or following unsafe abortion. Sexually transmitted infection (STI), urinary tract infection (UTI) and HIV/ AIDS are other diseases which are responsible to deteriorate women's health. On top of that, high prevalence of genital prolapse in rural Nepalese women is one of the biggest reproductive problems. Other common health problems in Nepalese women include menstrual and fertility problems, anemia and cancers in cervix, breast and ovaries.

There has been substantial improvement its RH status of women in the recent years with life expectancy at birth rising from 41 years in 1971 to 63.3 years in $2006 .{ }^{2}$ With a population of 25.8 million, maternal mortality ratio 281 per 100,000 live births, total fertility rate reduced to 3.1 and deliveries assisted by trained health personnel is only 19 percent (of live births) and 81 percent of births occur at home without the benefit of qualified birth attendants or doctors. ${ }^{3}$ The infant mortality rate is 48 per 1,000 live births. However there is relative lack of information or paucity of evidence based dimensions on reproductive morbidity (RM) which this aims to present.

\section{Methods}

Most studies of maternal morbidity from developing countries are hospital-based rather than communitybased, and most are retrospective rather than prospective. This study is a health camp based study involving women who attended mobile reproductive health camps in the villages.

The study was cross-sectional in design. It was conducted in Rautahat, Mahottari and Saptari districts located in the Terai region of Nepal. The study was done in women who attended four-week long health camps during December 2005 and 2006. The RH mobile camps were organized in different villages and surgical camps were conducted in the district headquarters

All the women $(n=7750)$ who came to seek healthcare at the RH camps were studied. The diagnoses were made mostly on clinical evaluation. Those women who gave history of complaints relating to reproductive tract were subjected to examination including bimanual and per speculum examination. The data were recorded and analyzed manually. Analysis was done by standard statistical methods.
The leading reproductive morbidity of pelvic organ prolapse (POP) was dealt with in some details in this study. Using the introitus as a reference point, a grade for genital prolapse was assigned. First degree equals prolapse present and extended to the introitus; second degree is when the prolapse exceeded the introitus at straining, and third degree is complete prolapse outside the introitus.

Analysis was done by standard statistical methods and a two tailed $\mathrm{P}$ value less than 0.05 was considered to indicate a significant difference.

\section{Results}

Of 7750 women examined in the three districts mentioned above during the study period, 5893 (76.2\%) had four major types of morbidity related to reproductive tract (Table 1$)$.

Table I: Distribution of women according to common RH morbidity

\begin{tabular}{lcc}
\hline Morbidity & Number & $\%$ \\
\hline STI & 2333 & 30.1 \\
POP & 1556 & 20.1 \\
Menstrual Disorders & 1295 & 16.7 \\
Sub-fertility & 719 & 9.3 \\
Others & 1857 & 23.8 \\
\hline Total & 7750 & 100 \\
\hline
\end{tabular}

STI formed the major bulk of morbidity $(30.1 \%)$ in the camps in Terai. They were treated as per the national guideline on STI but the husbands were not available for partner tracings. STI included vaginitis, cervicitis, pelvic inflammatory disease, etc but excluded HIV/ AIDS. The diagnoses were made on clinical evaluation and basic laboratory investigations.

Menstrual disorders were found in $16.7 \%$ of the women and it included irregular cycles, dysmenorrhea, scanty bleeding and amenorrhea, heavy or prolonged bleeding, etc. Sub-fertility was prevalent in $9.3 \%$ women. Primary sub-fertility was more common than the secondary sub-fertility (68\% versus $32 \%$ ). Other category included UTI, ANC, PNC, menopausal syndrome, gender based violence, fibroid uterus, acid peptic diseases, worm infestations, scabies, COPD, arthritis, polyneuropathies, etc.

There were no differences between 2005 and 2006 groups with regards to STI and menstrual disorder. However there was significant difference in POP, sub- 
Table 2. Comparison of RH morbidity in 2005 and 2006

\begin{tabular}{lccc}
\hline RH Morbidity & \multicolumn{1}{c}{2005} & 2006 & $\mathrm{P}(<0.05)$ \\
\hline STI & $31.4 \%(1129 / 3594)$ & $28.9 \%(1204 / 4156)$ & $\mathrm{NS}$ \\
POP & $27.3 \%(981 / 3594)$ & $13.8 \%(575 / 4156)$ & $\mathrm{S}$ \\
Menstrual Disorders & $19.1 \%(689 / 3594)$ & $14.5 \%(606 / 4156)$ & $\mathrm{NS}$ \\
Sub-fertility & $13.7 \%(492 / 3594)$ & $5.46 \%(227 / 4156)$ & $\mathrm{S}$ \\
Other Problems & $8.5 \%(303 / 3594)$ & $37 \%(1544 / 4156)$ & $\mathrm{S}$ \\
\hline
\end{tabular}

Numbers in parentheses indicate numerator and denominator of percent.

NS: Not Significant and S: Significant

fertility and other problems in the two years period where a large number of patients turned up with other medical illnesses too (Table 2).

POP formed the second major bulk of morbidity $(20.1 \%)$. Women suffered mostly from third degree uterovaginal prolapse and majority of them from procedentia. They were. $\mathrm{III}^{\mathrm{rd}}(38.6 \%), \mathrm{II}^{\text {nd }}(30 \%)$ and $\mathrm{I}^{\text {st }}(32 \%)$.

Treatment of POP offered are given in Table 3 and $23.3 \%$ of women with POP could receive surgical and others were fitted with ring pessary for surgery in future camps.

Table 3. Distribution of POP by treatment offered

\begin{tabular}{lcc}
\hline Treatment options & Number of women & $\%$ \\
\hline Ring pessary & 681 & 43.8 \\
Exercise & 512 & 32.9 \\
Surgery & 363 & 23.3 \\
\hline Total & 1556 & 100 \\
\hline
\end{tabular}

Age of women with POP ranged from 21- 92 years and in those who received surgery [ $n=363] ; 37 \%$ were fell in the age group of $40-49$ years, $6 \%$ in (20-29), $29.2 \%$ in (30-39), $>50(28.10 \%)$.

Parity is shown of women with POP ranged from para 1 to para 9 in this study. Maximum numbers of women with POP (65\%) were multipara (Fig 1).

Duration of suffering with POP ranged from 3 months to 51 years and they suffered 4 years $(23.7 \%), 5-9$ years (27\%), 10-14 years (22\%), 15-19years (16\%) and more than 20 years $(11.30 \%)$.

Some unusual cases seen (Fig 2-7) are self explanatory as illustrated: Cervical fibroid (Fig 2), concomitant rectal prolapse (Fig 3), vaginal carcinoma (Fig3), bladder stone (Fig 4), self inserted glass bangle (Fig 5) and neglected ring pessary inserted 45 years back.

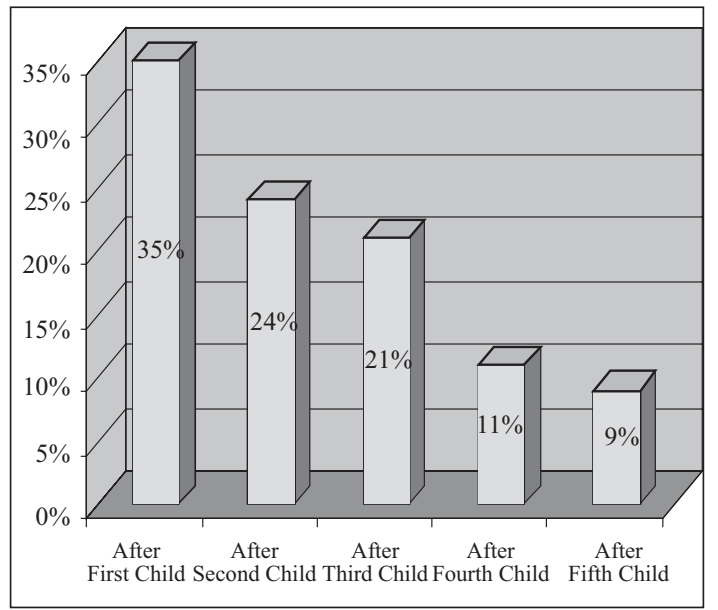

Figure 1: Onset of POP and parity among women receiving prolapse surgery

\section{Discussion}

Generally women with symptoms of reproductive morbidity do not seek treatment due to existing taboos and inhibitions regarding sexual and reproductive health. They often hesitate to discuss about their reproductive problems especially, due to shame and embarrassment ${ }^{4}$.

However, large number of patients with different reproductive morbidity came to the rural health camps in Terai seeking medical help. This showed the change in the scenario; women came to seek help if services were provided at their doorstep. Educating and empowering women to overcome the culture of silence surrounding reproductive organ disorders should be a priority in countries like Nepal.

According to WHO estimates, reproductive ill health accounts for 36 percent of the total disease burden in women as compared to 12.5 percent for males ${ }^{5}$. The report further states that osteoporosis, genital prolapse and other gynecological complications contribute significantly to reproductive morbidity. 


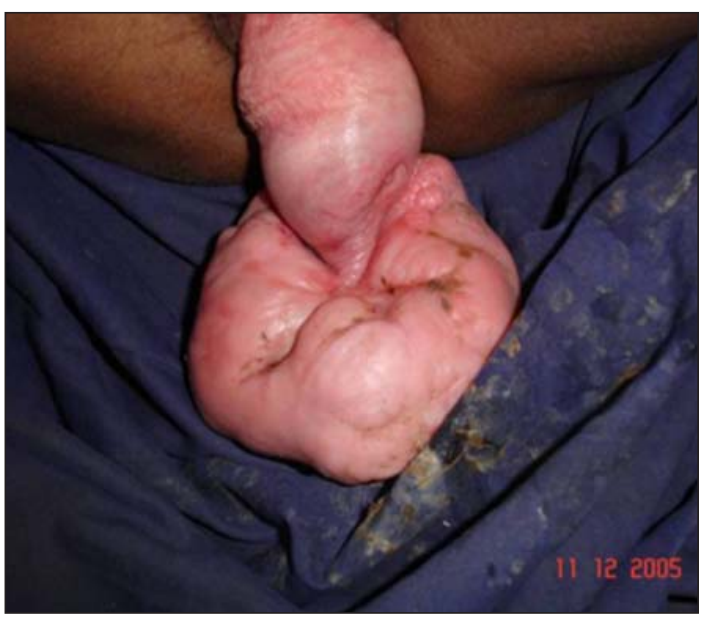

Fig 2. Huge cervical fibroid hanging along with the prolapsed uterus

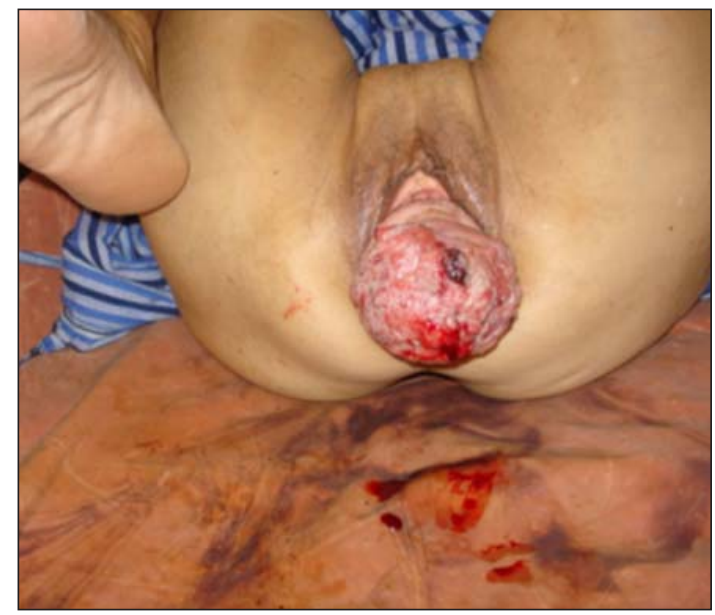

Fig 4. Malignancy in a long-standing prolapse

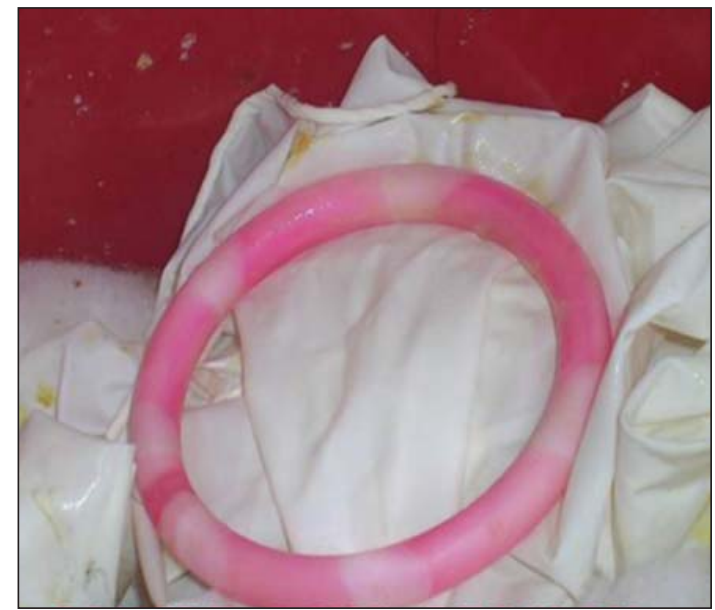

Fig 6. Real glass bangle used as pessary, removed in a health camp

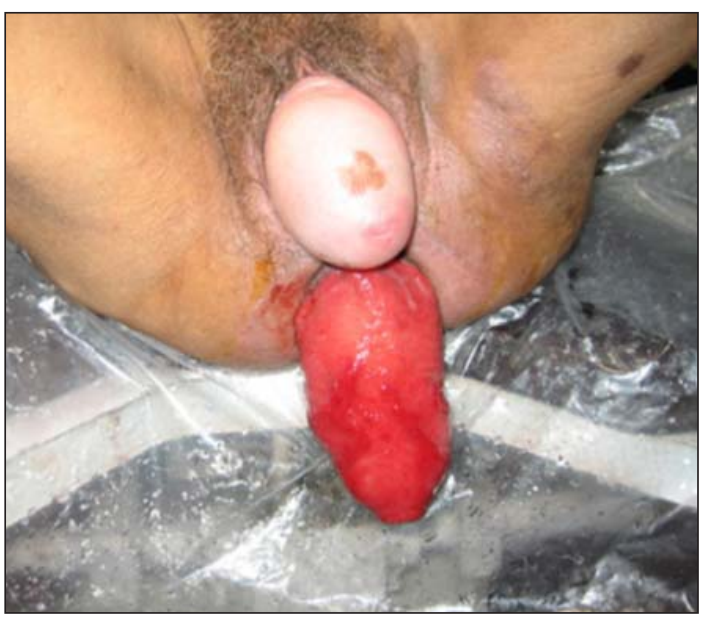

Fig 3. POP with concomitant rectal prolapse in a woman of 92 years old

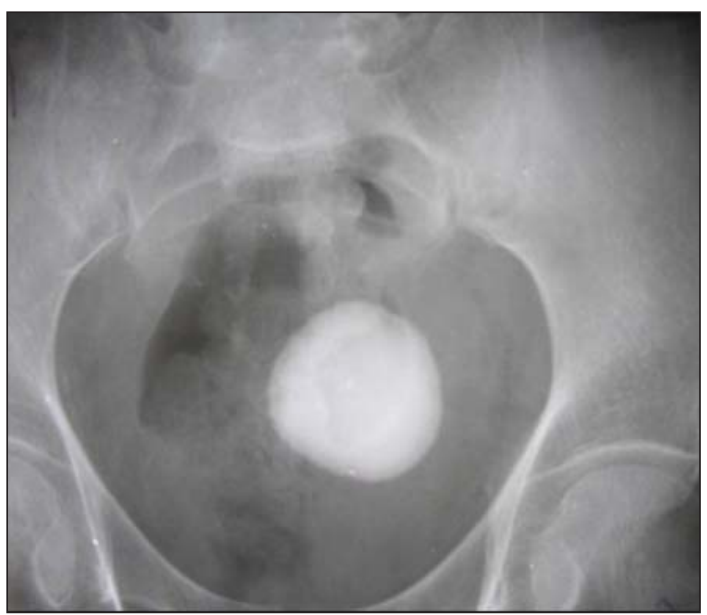

Fig 5. Bladder stone in a woman with POP after reducing the prolapse

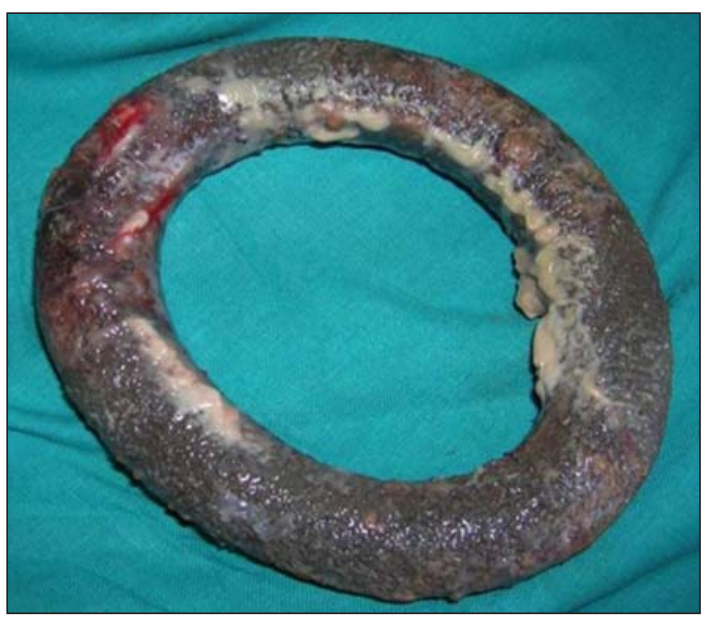

Fig 7. Forgotten ring pessary retrieved after 45 years. 
A study in rural India reports a very high level of reproductive morbidity. The study shows that more than half of the women are suffering from at least one or more RTI/STDs. ${ }^{6}$ RTI was the commonest RH morbidity in the present study too.

In a study in rural areas of the Gambia, seventy percent of the women had at least one reproductive organ disorder; most common were reproductive tract infections (47\%), childbirth-related damage to pelvic structures (46\%), menstrual dysfunction (34\%), and masses $(16 \%){ }^{7}$

In a clinic based reproductive health morbidity study conducted in far western districts of Nepal, 25.1\% represents pelvic organ prolapse $20.1 \%$ of RTI, $17.1 \%$ of infertility and $12.3 \%$ of menstrual disorders. ${ }^{8}$

In a camp based study in western Nepal, the prevalence of POP was $18 \%$ followed by RTI (14\%), sub-fertility (14\%) and menstrual disorders (7\%). ${ }^{9}$

In the present study, four major reproductive problems in the Terai were STI (30\%), POP (20\%), menstrual disorders $(17 \%)$ and sub-fertility $(9 \%)$. Four major morbidity were the same in both the studies.

Menstrual disorders in the form of irregular cycles, dysmenorrhea, heavy or prolonged bleeding, amenorrhea, etc constitute an important unaddressed area of reproductive health service needs in developing countries for which relatively simple and inexpensive therapies are often available. The prevalence of menstrual disorders in the present study was $17 \%$.

Violence against women is a deep rooted problem in Nepal. The dowry system in Terai and some other parts of Nepal humiliates and tortures the females physically and mentally. In this study, gender based violence was very high with $72 \%$ of the screened women identified as having GBV. Family/ spousal conflict, genital prolapse, son preference, sub-fertility, alcohol abuse, unwanted sexual relationship, polygamous marriage, etc. were the causes of gender based violence in Terai. The major types of violence prevalent in the Terai were domestic violence, marital rape and sexual violence.

Pelvic organ prolapse is a very common condition, particularly among older women. Prolapse may be defined as the falling or slipping out of place of a part or viscus. POP is the abnormal descent or herniation of the pelvic organs from their normal attachment sites or their normal position in the pelvis (into the vagina), often accompanied by urinary, bowel, sexual, or local symptoms. ${ }^{10}$
It is estimated that a half of parous women lose pelvic floor support, resulting in some degree of prolapse and that of these women, $10-20 \%$ seek medical care..$^{11}$ The global prevalence of genital prolapse is estimated to be $2-20 \%$ in women under age $45 .{ }^{12}$

In a general population of women, 20 to 59 years of age in Sweden, the prevalence of any degree of prolapse was $30.8 \% .^{13}$

In rural Egypt high levels of gynecological morbidity was found. Fifty-six percent of all women had genital prolapse, and the risk increased both with a woman's age and number of deliveries. ${ }^{14}$

In a community based study in Nepal, commissioned by UNFPA, the prevalence of POP was $10 \%$ in the reproductive age group and majority $(46 \%)$ was in the age-group of 30-49. ${ }^{15}$

In the present study, prevalence of POP was $20 \%$ and majority $(37 \%)$ of women who underwent prolapse surgery was in the age group of 40-49. Two-thirds (66\%) were in the age group of 30-49. More than one third (35\%) developed POP after first child birth and nearly $60 \%$ had POP after first and second childbirth. Majority (27\%) suffered from POP for 5-9 years.

These findings are in line with another study conducted in Terai among rural population. In that study, the prevalence of POP was $37 \%$. Thirty-eight percent developed POP after birth of first child, 22\% suffered from POP for 5-10 years and average duration of suffering was 11 years. ${ }^{16}$

In a study by UNFPA in rural Nepal, mean duration of suffering from POP was found to be 7.8 years and $35 \%$ women suffered from POP for 5-10 years. ${ }^{15}$

In a study in Western hills of Nepal, the average age of onset of POP was 27 and 58 percent had completed two pregnancies or fewer at time of onset. ${ }^{17}$

Even the adolescents suffered from POP $(22.2 \%-23.5 \%)$ in Achham and Doti; women in age group of $20-29$ years suffered from $43.8 \%-44.6 \%$ of POP in both districts and 10 years was the mean duration of suffering from POP. ${ }^{8}$

POP is assumed to be induced by child birth in much younger population which results in long years of suffering beginning relatively from a younger age. The findings of the current study show similarities with other researches in Nepalese population. ${ }^{8,15,16}$ 


\section{Conclusion}

The major reproductive morbidity in the Terai were STI, POP, menstrual disorders and sub-fertility. Although there was overwhelming number of women who needed surgical correction of POP only a fourth could avail the service due to the lack of resources thus denoting a necessity of more supervised delivery than correction of prolapse in the surgical camps.

\section{Acknowledgments}

Would love to thank Dr. Bharat Pradhan and Dr. Basanta Maharjan of Kathmandu Model Hospital for their assistance during various phases and also to Dr. Sanjaya Dhakal in preparation of this paper and lastly to UNFPA Country Office, Nepal for funding this project.

\section{References}

1. International Conference on Population and Development: Context and Characteristics. Policy and Research Paper, no. 7, Cairo; 1994.

2. Central Bureau of Statistics (CBS). Nepal in Figure. Kathmandu: CBS; 2006.

3. Nepal Demographic and Health Survey (NDHS). Kathmandu: Department of Health Services; 2006

4. Bang R, Bang A. A community study of gynecological diseases in Indian villages. In: Zeidenstein and Moore, eds.Learning about Sexuality: A Practical Beginning. New York: Population Council; 1989.

5. World Health Organization (WHO). The Global Burden of Disease. Geneva: WHO; 1996.

6. Joseph A, Jasmin P, Abraham S. Gynecological problems among young married women in Tamil Nadu, Paper presented in an International Conference on Adolescent Reproductive Health: Evidence and Programme Implications for South Asia, Mumbai, India; 2000.

7. Walraven G, Scherf C, West B, Ekpo G, Paine K, Coleman $\mathrm{R}$, et al. The burden of reproductiveorgan disease in rural women in Gambia, West Africa. Lancet 2001;357(9263):1161-1167
8. Bonetti T R. Erpelding A, Pathak LR. Reproductive Morbidity- a neglected issue? A report of a clinic based study held in Far-Western Nepal. Kathmandu, Nepal: Ministry of Health, GTZ and UNFPA; 2002.

9. Tuladhar H. An overview of reproductive health of women in Bajhang district. Nepal Med Coll J 2005; 7(2):107-11

10. Dangal G. A brief overview of genital prolapse in women. Nepal Journal of Science and Technology 2006; (6): 129-132

11. Beck RP. Pelvic relaxation prolapse. In: Kase NG, Weingold $A B$, eds. Principles and practice of clinical gynecology. New York: John Wiley; 1983:677-685

12. World Health Organization (WHO). Report on the region reproductive health strategy workshop: South -East Asia Region. Geneva: WHO; 1995

13. Samuelsson EC, Arne Victor FT, Tibblin G, Svardsudd KF. Signs of genital prolapse in a Swedish population of women 20 to 59 years of age and possible related factors. Am J Obstet Gynecol 1999; 180(2 Pt 1):299-305

14. Younis N, Khattab H, Zurayk H, El-Mouelhy M, Fadle Amin M, Moneim Farag A. A community study of gynecological and related morbidities in rural Egypt. Studies in Family Planning 1993; 24(3):175-186

15. Geeta Gurung, Ashma Rana, Archana Amatya, Keshang D. Bista, Ananda B. Joshi, Jamuna Sayami. Pelvic organ prolapse in rural Nepalese women of reproductive age groups: What makes it so common? N J Obstet Gynaecol 2007; 2 (2): $35-41$

16. Pradhan S. Unheeded Agonies- A study of uterine prolapse prevalence and causes in Siraha and Saptari districts. Kathmandu Women's Reproductive Rights Program- Centre for AgroEcology and Development; 2007

17. Bonetti TR, Erpelding A, Pathak LR. Listening to "felt needs": investigating genital prolapse in western Nepal. Reproductive Health Matters 2004;2(23):166-175 